\title{
Feasibility and Health Benefits of an Individualized Physical Activity Intervention in Women With Metastatic Breast Cancer: Intervention Study
}

Lidia Delrieu ${ }^{1,2}, \mathrm{PhD}$; Vincent Pialoux ${ }^{1,3,4}, \mathrm{PhD}$; Olivia Pérol ${ }^{2}, \mathrm{MSc}$; Magali Morelle ${ }^{5}, \mathrm{MSc}$; Agnès Martin ${ }^{6}, \mathrm{MSc}$; Christine Friedenreich ${ }^{7,8,9}$, PhD; Olivia Febvey-Combes ${ }^{5}$, MD, MPH; David Pérol ${ }^{5}$, MD, MPH; Elodie Belladame ${ }^{2}$, MSc; Michel Clémençon ${ }^{1,10}$, PhD; Eva Roitmann ${ }^{11}$, MSc; Armelle Dufresne ${ }^{12}, \mathrm{MD}, \mathrm{PhD}$; Thomas Bachelot ${ }^{12}$, MD; Pierre Etienne Heudel $^{12}$, MD; Marina Touillaud ${ }^{2,13}$, PhD; Olivier Trédan ${ }^{12}, \mathrm{MD}, \mathrm{PhD}$; Béatrice Fervers ${ }^{2,13}$, MD, PhD

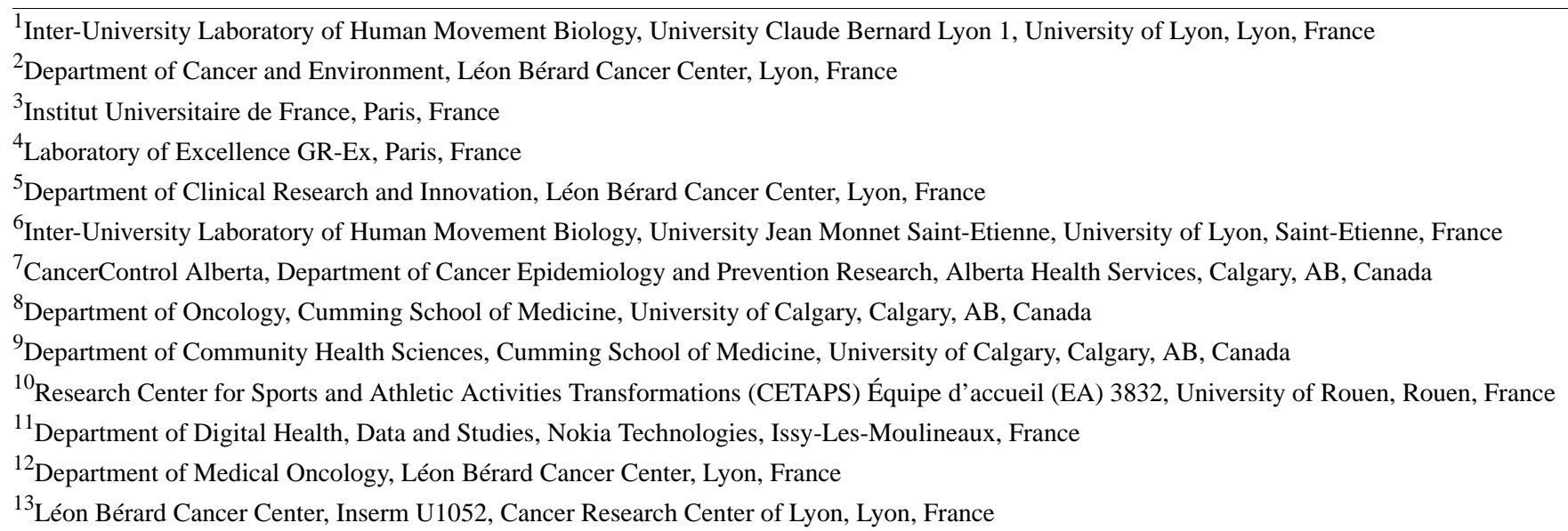

\section{Corresponding Author:}

Béatrice Fervers, MD, PhD

Department of Cancer and Environment

Léon Bérard Cancer Center

28 rue Laënnec

Lyon, 69008

France

Phone: 330478782800

Email: beatrice.fervers@lyon.unicancer.fr

\section{Abstract}

Background: There is limited knowledge regarding the potential benefits of physical activity in patients with metastatic breast cancer.

Objective: The Advanced stage Breast cancer and Lifestyle Exercise (ABLE) Trial aimed to assess the feasibility of a physical activity intervention in women with metastatic breast cancer and to explore the effects of physical activity on functional, psychological, and clinical parameters.

Methods: The ABLE Trial was a single-arm, 6-month intervention study with a home-based, unsupervised, and personalized walking program using an activity tracker. At baseline and 6 months, we assessed anthropometrics, functional fitness, physical activity level, sedentary behavior, quality of life, fatigue, and tumor progression. Paired proportions were compared using the McNemar test and changes of parameters during the intervention were analyzed using the Wilcoxon signed-rank test, the Mann-Whitney test, and Spearman rank correlations.

Results: Overall, 49 participants (mean age 55 years; recruitment rate $94 \%$ ) were enrolled and $96 \%$ adhered to the exercise prescription (attrition rate $2 \%)$. Statistically significant improvements in the 6-minute walking distance test $(+7 \%, P<.001)$ and isometric quadriceps strength $(+22 \%, P<.001)$, as well as decreases in body mass index $(-2.5 \%, P=.03)$ and hip circumference 
$(-4.0 \%, P<.001)$ were observed at 6 months. Quality of life remained stable and a nonstatistically significant decrease $(-16 \%$, $P=.07)$ in fatigue was observed.

Conclusions: The high recruitment and adherence rates suggest the willingness of patients with metastatic breast cancer to participate in a physical activity program. The beneficial outcomes regarding physical fitness and anthropometry of this unsupervised physical activity program may encourage these patients to maintain a physically active lifestyle. Future randomized controlled trials with larger sample sizes are warranted.

Trial Registration: ClinicalTrials.gov NCT03148886; https://clinicaltrials.gov/ct2/show/NCT03148886

(JMIR Mhealth Uhealth 2020;8(1):e12306) doi: 10.2196/12306

\section{KEYWORDS}

metastatic breast cancer; physical activity; activity trackers; feasibility; tumor progression

\section{Introduction}

Metastatic breast cancer remains an incurable disease, but treatments help maintain or improve quality of life and prolong overall survival through the control of symptoms [1-3]. Despite therapeutic advances, a decrease in quality of life in patients with metastatic breast cancer between 2005 and 2015 has been reported [4]. With metastatic disease, several domains of quality of life are affected from the time of diagnosis, with a decrease in physical, social, and role functioning and an increase in symptom burden, such as insomnia, fatigue, and pain, that deteriorate in advanced and palliative cancer [5].

In early-stage breast cancer, physical activity has been shown to reduce fatigue and side effects of treatments, increase quality of life, and limit physical deconditioning [6-8]. Thus far, there is limited knowledge regarding the potential benefits of physical activity in patients with metastatic breast cancer despite patients' needs and their desires to engage in exercise $[9,10]$. The new guidelines from the Macmillan Foundation for people with metastatic bone disease have highlighted the importance of remaining as physically active as possible and limiting sedentary behavior, despite the side effects of the disease and its treatment [11]. A review of physical activity in palliative cancer patients has shown that patients with metastatic cancer who walked 30 minutes or more per day reported a higher quality of life than those who walked less than 30 minutes per day [12]. However, the effect of physical activity in patients with metastatic breast cancer remains controversial, especially concerning quality of life [10], possibly because few physical intervention studies have focused on patients with metastatic breast cancer. Hence, there is a need for additional studies to determine the benefit of physical activity on patient-reported outcomes for this population.

Activity trackers are emerging as a means to motivate populations to increase their physical activity level to personal or recommended goals $[13,14]$ as a result of the feedback received in real time (eg, steps) [13,15]. The benchmark performance of 10,000 steps per day for healthy populations has been associated with a reduced risk of cardiovascular disease, better psychological well-being, weight loss, and improved body composition [16]. However, for adults with health impairment such as disability and/or chronic illness, reducing sitting time, which is a recognized marker of sedentary behavior [17], and achieving 5000-7000 steps per day that

correspond to a low active population, may be more appropriate targets than 10,000 steps per day [18].

The primary aim of the Advanced stage Breast cancer and Lifestyle Exercise (ABLE) single-arm Trial was to determine the feasibility of an unsupervised and personalized 6-month physical activity intervention, performed with activity trackers under real-life conditions, in patients with metastatic breast cancer. The secondary aims were to investigate changes in (1) physical activity, sedentary behavior, and physical fitness, (2) anthropometric measurements, (3) quality of life and fatigue, and (4) tumor progression, as well as their associations with the performed physical activity.

\section{Methods}

\section{Study Design}

The ABLE Trial was a single-arm intervention study in patients with metastatic breast cancer conducted at the Léon Bérard Comprehensive Cancer Centre, Lyon, France. The ABLE Trial protocol has been published previously [19]. The protocol was approved by the French Ethics Committee (Comité de Protection des Personnes Sud-Est IV). The study was reported to the National Commission for Data Protection and Liberties (CNIL; reference number: 1994192) and registered at ClinicalTrials.gov (trial number: NCT03148886).

Briefly, participants were identified during the weekly multidisciplinary board meeting for metastatic breast cancers. The study was proposed by medical oncologists to eligible patients being treated with chemotherapy at the day care unit. Patients treated with hormone therapy received an information letter signed by their oncologist and a study brochure via postal mail; a clinical research assistant contacted them by telephone one week later to know whether they agreed to be enrolled in the study. All patients provided written informed consent prior to their inclusion into the study.

\section{Study Participants}

Women were eligible to participate in the study if they were between 18 and 78 years of age, with de novo or secondary metastatic breast cancer that has been histologically confirmed. Subjects needed to be newly diagnosed patients (ie, within the last 3 months) in order to have comparable patients at inclusion. Patients were treated with chemotherapy, hormone therapy, targeted therapy, and/or radiation therapy. Additional eligibility criteria were as follows: having a medical clearance of no 
contraindications to physical activity; having an Eastern Cooperative Oncology Group performance status of less than 2; being able to speak and understand French, to complete questionnaires, and to follow instructions in French; and having a valid health insurance affiliation. An active list of patients was extracted from the center's data to estimate the number of potential subjects and the age range for the inclusion criteria. These data were extracted from the numbers of patients treated at the center in 2015 for metastatic breast cancer with our inclusion criteria.

Patients with contraindications to physical activity (eg, uncontrolled hypertension or cardiac disease and unstable bone metastases) who were unable to be followed for medical, social, familial, geographical, or psychological reasons over the study period, or with deprivation of liberty by court or administrative decision, were deemed ineligible for the ABLE Trial.

\section{Exercise Intervention}

The intervention was a 6-month, home-based, unsupervised, personalized physical activity program based on international physical activity recommendations and was based on a goal of a number of steps to reach per day [19]. Participants were asked to wear a wrist activity tracker during the duration of the intervention (Nokia Go wristband, Nokia France). Based on their health status at baseline and the average number of steps registered during the first week, women received an individual goal of steps per day from a physical activity instructor. The goal was reviewed weekly and revised depending on the number of steps performed during the previous week, the participant's feelings, and her health status. The target number of steps was set within a maximum of 1000 steps above the average number of steps in the previous week. For participants who reached 10,000 steps per day, the target was to maintain their number of daily steps. For patients who found it difficult to reach the goal of daily step number, their goal could be lowered so that the new goal could be reached according to the patients' abilities and in accordance with the recent recommendations for the practice of physical activity in cancer patients [20]. To apply the intervention, we used two strategies. First, we adapted the number of steps to make it reasonably achievable because people need to experience the satisfaction of achieved goals in order to have the pleasure of mastery and to allow the participant to set goals and stay motivated. Second, there were times participants could have discussions with the physical activity professional to encourage evaluative feedback and encouragement, which contributes to social persuasion. Every week, all participants received the following from the physical activity instructor, either in person or by phone: individual feedback on their performance and personalized recommendations to increase or maintain their physical activity and reduce sedentary behavior.

\section{Outcome Measures}

The primary outcome is the feasibility of the intervention assessed with the proportion of participants achieving the international physical activity recommendations of 150 minutes per week of at least moderate-intensity physical activity [21], which was evaluated by the long form of the International Physical Activity Questionnaire (IPAQ) [22] during the last week of the study. Very little is known about this population and since we were not sure that participants would adhere to the activity tracker, an objective that could be measurable by questionnaire for all patients was chosen.

The adherence rate to the exercise program was calculated as the proportion of patients from the full study population who used the physical activity tracker throughout the duration of the study without interruption for more than one consecutive week. Secondary outcomes were the changes during the intervention in (1) the score of total physical activity and time spent in sedentary activities as assessed by the long-form IPAQ, and physical fitness assessed by the performance of the 6-minute walk test and the upper- and lower-limb strengths, (2) anthropometrics, (3) scores of quality of life and fatigue, and (4) both the progression rate and the overall survival—estimated by Kaplan-Meier analysis - to assess the disease evolution.

\section{Data Collection}

\section{Overview}

Parameters were assessed at baseline (T1) and at the end of the intervention at 6 months (T2). To assess survival, the vital status of the study participants was checked on June 2018 through the participants' electronic medical records after they had completed the intervention.

\section{Demographic and Clinical Data}

Demographics, including birth date, age at diagnosis, living situation, and employment status, were collected at baseline [19]. All clinical data were extracted from the participants' electronic medical records: hormone receptor status for both estrogen and progesterone receptors, tumor histology, personal history of breast cancer, sites of metastases, number of metastatic sites, and current treatment. The Response Evaluation Criteria In Solid Tumors (RECIST) V1.1 was used to assess tumor progression between diagnosis and the end of the physical activity intervention [23].

\section{Physical Activity Level and Sedentary Behavior}

Physical activity was evaluated by the long-form IPAQ score over the past week [22]. The long-form IPAQ is a validated self-administered physical activity questionnaire that has good reliability [22] and is comprised of 31 items grouped into four activity domains: work-related, transportation-related, domestic, and recreational physical activity [22]. The IPAQ provides scores-expressed in metabolic equivalent of task (MET)-minutes/week—-separately for walking, moderate-intensity activity (ie, 3-6 METs), and vigorous-intensity activity (ie, >6 METs) within each of the work, transportation, and domestic chores, as well as the gardening and leisure-time domains. Sedentary activities were assessed using sitting time-in minutes/week-measured by the IPAQ questionnaire. The global IPAQ score was computed by summing the scores of each physical activity domain, then dividing into three categories of physical activity level used by the World Health Organization: low (<600 MET-minutes/week), moderate ( $\geq 600$ and $<3000$ MET-minutes/week), and vigorous ( $\geq 3000$ MET-minutes/week) physical activity [21]. To assess compliance with the 150 minutes/week physical activity 
recommendations, we used the average intensity of 4.2 METs for moderate-intensity activities that these women were likely to perform (ie, computed as the mean of common moderate-intensity activities, including 3.8 METs for cleaning, 5.3 METs for hiking, 3.5 METs for walking for pleasure, and 4.3 METs for walking for exercise). Thus, participants reached the 150-minute physical activity recommendations if they achieved at least the threshold of 630 MET-minutes/week (ie, 150 minutes multiplied by 4.2 METs).

The number of steps per day measured by the wrist activity tracker was collected by regular transfer through the activity tracker mobile phone app (Nokia Health Mate) available on the participants' mobile phones or tablet PCs. For participants with no mobile phone, the number of steps was transferred when they came to the hospital for their weekly or biweekly consultation. Data were uploaded to the study phone and a screenshot was taken that was then sent to the participant by email. The physical activity instructor was able to use the activity tracker interface to monitor the number of daily steps and any change in the activity level in order to set the target number of daily steps and adapt physical activity recommendations.

\section{Physical Fitness}

During the 6-minute walk test, participants were asked to perform the maximum walking distance, in meters, during 6 minutes (ie, 6-minute walking distance [6MWD]) on a 30-meter-long flat corridor, while oxygen uptake consumption (computed as $\mathrm{VO}_{2 \text { peak }}$ ) and heart rate were recorded using a portable respiratory gas analyzer (MetaMax 3b, Cortex Biophysik).

The maximum upper-limb strength in kilograms and lower-limb strength in Newtons were measured using a hand dynamometer (Jamar Plus Digital Hand Dynamometer, Patterson Medical) and a back-leg dynamometer (DFS II Series Digital Force Gauges, Chatillon), respectively [24]. Two measures were performed on each hand and on the dominant leg and the best performances were registered.

\section{Anthropometrics}

Assessment of anthropometrics included measurements of standing height in centimeters, body weight in kilograms, and waist and hip circumferences in centimeters as well as the calculation of body mass index (BMI) in $\mathrm{kg} / \mathrm{m}^{2}$; metabolic risk, defined as waist circumference to height ratio of $>0.5$ [25]; risk of insulin resistance, defined as waist circumference of $>80 \mathrm{~cm}$; and cardiovascular risk, defined as waist circumference of $>88 \mathrm{~cm}$ [26].

\section{Participant-Reported Outcomes}

Quality of life was assessed using the European Organization for Research and Treatment of Cancer (EORTC) Quality of Life Questionnaire (QLQ-C30), a 30-item, self-administered questionnaire that evaluates a global quality-of-life domain, five functional domains (ie, physical, role, emotional, cognitive, and social), three symptom domains (ie, pain, fatigue, and nausea), and six single items (ie, dyspnea, insomnia, appetite loss, diarrhea, constipation, and financial impact) [27].
Fatigue was assessed by the global score of fatigue obtained from the EORTC QLQ-C30 and by the revised 22-item, self-report Piper Scale containing four subscales: behavioral and severity, affective, sensory, and cognitive and mood $[27,28]$.

Social deprivation was assessed by the score of the Evaluation of Precarity and Inequalities in Health Examination Centers (EPICES) questionnaire based on 11 socioeconomic questions $[29,30]$. The score ranges from 0 (the least deprived) to 100 (the most deprived); social vulnerability is defined with a score of $\geq 30.17$.

\section{Statistical Analysis}

Participants' characteristics were described using means and SDs or $95 \%$ CIs for quantitative data and were described with frequencies and percentages for qualitative data.

The recruitment rate was calculated as the proportion of participants who provided informed consent to participate in the ABLE Trial among eligible participants to whom the study was presented. The reasons for refusal were described.

For the primary outcome, paired proportions before and after the intervention were compared using the McNemar test. For secondary outcomes, changes of continuous parameters during the physical activity intervention were analyzed using nonparametric tests, since the distributions of physical activity data were highly skewed. The algorithm of the activity trackers detects when subjects do not wear it using an integrated triaxial accelerometer. Therefore, the analyses only included the days when the subjects wore their activity trackers. The evolution of the number of steps by days was analyzed with an unconditional growth model, a model with number of days as the only level 1 predictor and no substantive predictors at level 2. For the unconditional linear growth model, the level 1 model is as follows:

$$
\text { Step }_{i t}=\prod_{o i}+\prod_{l i} \text { Time }_{i j}+\varepsilon_{i j}(1)
$$

The level 2 model is as follows:

$$
\Pi_{o i}=\gamma_{00}+\varphi_{0 i} \text { and } \prod_{l i}=\gamma_{10}+\varphi_{1 i}(2)
$$

In the level 2 model, the population-level estimates (ie, $\gamma_{00}$ and $\left.\gamma_{10}\right)$ are referred to as the fixed effects. The individual deviations (ie, $\varphi_{0 \mathrm{i}}$ and $\varphi_{1 \mathrm{i}}$ ), which can be thought of as the level 2 residuals, are referred to as the random effects. Overall survival was estimated using the Kaplan-Meier method. Median follow-up time was calculated using a reverse Kaplan-Meier estimate. Multivariate analyses were not possible given the limited sample size. Exploratory analyses on the relationship between variables were performed using Spearman rank correlations or Mann-Whitney tests when appropriate. The quality-of-life scores of the participants were compared with reference values for women with recurrent or metastatic breast cancer with a one-sample $t$ test [31]. All $P$ values under .05 were considered statistically significant. As the result of the exploratory setting of the analyses, no adjustments were performed in this feasibility study.

Data were analyzed using SAS software, version 9.4. (SAS Institute Inc). 


\section{Results}

\section{Recruitment and Follow-Up}

Participants were recruited between October 27, 2016, and January 26, 2018. Among 425 patients screened, 54 (12.7\%) were eligible (see Figure 1), then 3 declined to participate (acceptance rate of 94\% [51/54], 95\% CI 88.9-100.0). Another
2 participants were excluded because they were found not to have metastatic breast cancer. Overall, 49 women with metastatic breast cancer completed the baseline assessment, 1 participant dropped out after 3 months (attrition rate of $2 \%$ [1/49]), and 4 participants died from breast cancer before the end of intervention (see Figure 1). The participants were followed for their vital status over a total median time of 12.7 months (95\% CI 11.0-14.2).

Figure 1. Flowchart of the Advanced stage Breast cancer and Lifestyle Exercise (ABLE) Trial.

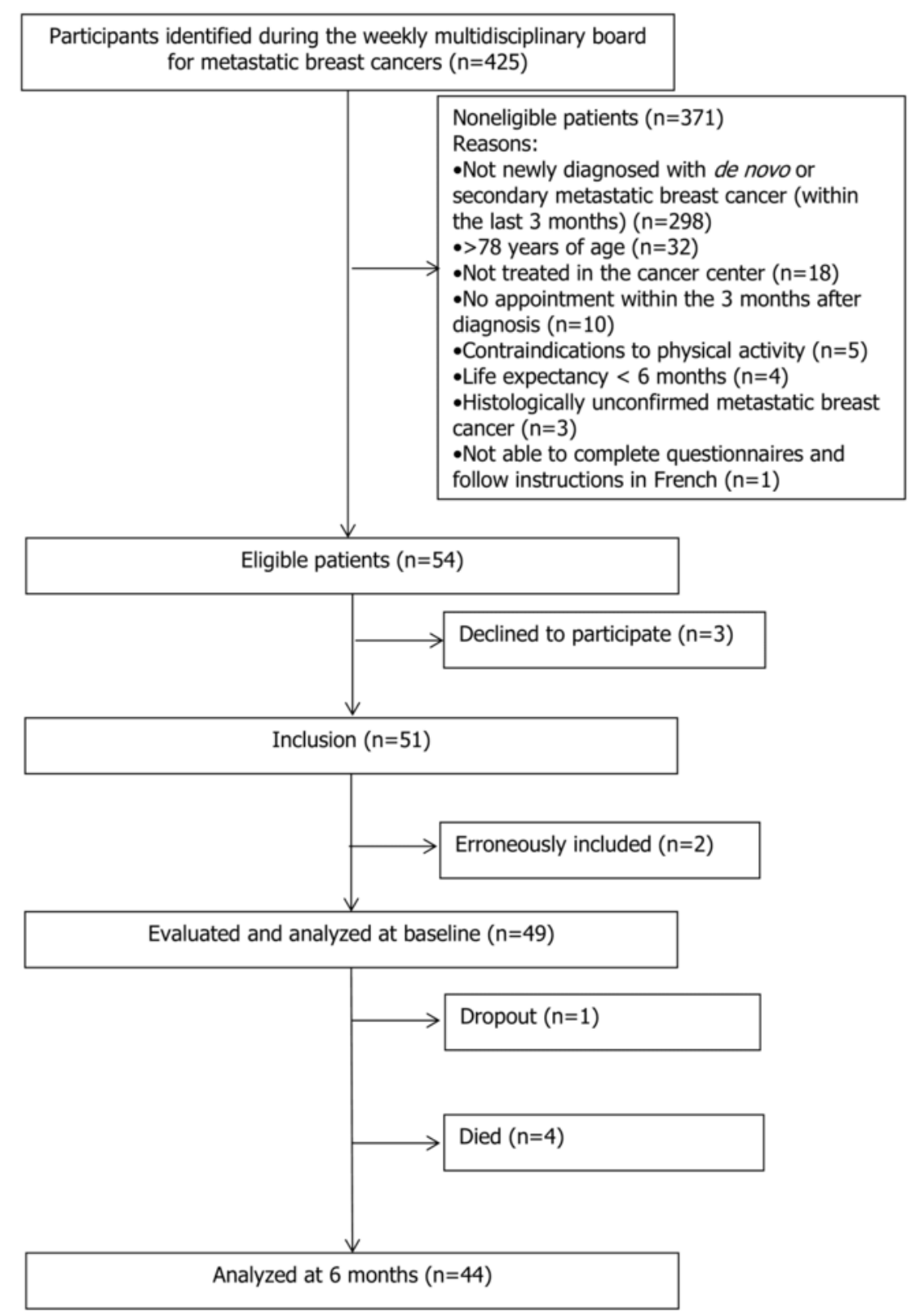

\section{Participants' Characteristics}

At baseline, the mean age of the study participants was 55 years (SD 10). Most of them were not working (81\%), had high education (ie, higher than or equal to high school, 67\%), and were not considered socially vulnerable (67\%) (see Table 1). A majority $(71 \%)$ of participants presented with distant metastatic recurrence and $29 \%$ presented with de novo metastatic breast cancer. Among the women with distant metastatic recurrence, the mean time from de novo breast cancer diagnosis to metastatic recurrence was 94.3 months (SD 79.1). With respect to breast cancer subtypes, most women presented with positive hormone receptor status $(71 \%), 26 \%$ had triple-negative breast cancer, and $2 \%$ overexpressed human epidermal growth factor receptor 2 (HER2). Most of the participants $(67 \%)$ had bone metastases. The majority of participants $(55 \%)$ were receiving hormone therapy and $45 \%$ received chemotherapy as first-line treatment. 
Table 1. Demographics and baseline clinical characteristics of women with metastatic breast cancer in the ABLE ${ }^{\mathrm{a}}$ Trial, $(\mathrm{N}=49)$.

\begin{tabular}{|c|c|}
\hline Characteristics & Mean (SD) or n $(\%)$ \\
\hline \multicolumn{2}{|l|}{ Clinical } \\
\hline Age at inclusion, mean (SD) & $55(10)$ \\
\hline De novo metastatic breast cancer, n (\%) & $14(29)$ \\
\hline Secondary metastatic breast cancer, $\mathrm{n}(\%)$ & $35(71)$ \\
\hline \multicolumn{2}{|l|}{ Breast cancer histological subtypes, $\mathrm{n}(\%)$} \\
\hline Hormone positive receptor & $35(71)$ \\
\hline HER $2+{ }^{b}$ & $1(2)$ \\
\hline Triple negative & $13(27)$ \\
\hline Number of metastatic localizations, mean (SD) & $4.7(3.1)$ \\
\hline \multicolumn{2}{|l|}{ Locations of metastasis ${ }^{\mathrm{c}}, \mathbf{n}(\%)$} \\
\hline Bones & $33(67)$ \\
\hline Visceral & $27(55)$ \\
\hline Brain & $6(12)$ \\
\hline \multicolumn{2}{|l|}{ Treatment at inclusion $^{\mathrm{c}}, \mathrm{n}(\%)$} \\
\hline Chemotherapy & $22(45)$ \\
\hline Hormone therapy & $27(55)$ \\
\hline Targeted therapy & $21(43)$ \\
\hline \multicolumn{2}{|l|}{ Demographics, n (\%) } \\
\hline \multicolumn{2}{|l|}{ Employment status } \\
\hline Working & $9(18)$ \\
\hline Sick leave & $19(39)$ \\
\hline Retired & $11(22)$ \\
\hline Unemployed & $10(20)$ \\
\hline \multicolumn{2}{|l|}{ Education } \\
\hline No diploma & $5(10)$ \\
\hline Middle school & $11(22)$ \\
\hline High school & $9(18)$ \\
\hline 1- to 2-year university degree & $13(27)$ \\
\hline 3- to 4-year university degree & $6(12)$ \\
\hline$\geq 5$-year university degree & $5(10)$ \\
\hline \multicolumn{2}{|l|}{ Social vulnerability score } \\
\hline$<30$ & $33(67)$ \\
\hline$\geq 30$ & $16(33)$ \\
\hline
\end{tabular}

${ }^{\mathrm{a}}$ ABLE: Advanced stage Breast cancer and Lifestyle Exercise.

${ }^{b}$ HER2+: tested positive for human epidermal growth factor receptor 2 (HER2).

${ }^{\mathrm{c}}$ The values do not add up to 49 (100\%) because several responses could be reported by each participant.

At baseline, the average total physical activity level as measured by the IPAQ questionnaire was 2031 MET-minutes/week (SD 2213); 14 (29\%) participants had achieved light physical activity level (<600 MET-minutes/week), 23 (47\%) had achieved moderate physical activity level $(\geq 600$ and $<3000$ MET-minutes/week), and 12 (25\%) had achieved vigorous physical activity level ( $\geq 3000$ MET-minutes/week) (see Table
2). Participants walked an average of 451 meters during the 6MWD and 5593 steps per day, and 69\% achieved the physical activity recommendations. The mean BMI was $26.1 \mathrm{~kg} / \mathrm{m}^{2}$ (SD 5.8). The global health score assessed with the EORTC QLQ-C30 was 63, and 61\% of the patients declared fatigue at baseline. 
Table 2. Change in anthropometric measures, physical fitness, and patient-reported outcomes in the $\mathrm{ABLE}^{\mathrm{a}} \mathrm{Trial}$

\begin{tabular}{|c|c|c|c|}
\hline Measure & $\begin{array}{l}\text { Baseline }(\mathrm{N}=49) \\
\text { mean }(\mathrm{SD}) \text { or } \mathrm{n}(\%)\end{array}$ & $\begin{array}{l}\text { End of the study }(\mathrm{N}=44) \text {, } \\
\text { mean }(\mathrm{SD}) \text { or } \mathrm{n}(\%)\end{array}$ & $P$ value \\
\hline \multicolumn{4}{|l|}{ Physical activity level } \\
\hline \multicolumn{4}{|l|}{ IPAQ $^{b}$} \\
\hline Total physical activity $\left(\mathrm{MET}^{\mathrm{c}}\right.$ - minutes/week), mean (SD) & $2031(2213)$ & $1940(1762)$ & .66 \\
\hline \multicolumn{4}{|l|}{ Level of physical activity, $n(\%)$} \\
\hline Light physical activity (<600 MET-minutes/week) & $14(29)$ & $10(23)$ & .42 \\
\hline Moderate physical activity ( $\geq 600$ and $<3000$ MET-minutes/week) & $23(47)$ & $25(57)$ & .42 \\
\hline Vigorous physical activity (>3000 MET-minutes/week) & $12(24)$ & $9(20)$ & .42 \\
\hline \multicolumn{4}{|l|}{ Type of physical activity, mean (SD) } \\
\hline Work-related physical activity (MET-minutes/week) & $182.3(612.7)$ & $410.2(1147.0)$ & .43 \\
\hline Transportation-related physical activity (MET-minutes/week) & $357.3(631.1)$ & $208.3(234.5)$ & .32 \\
\hline Domestic physical activity (MET-minutes/week) & $980.8(1423.0)$ & $471.6(587.2)$ & .004 \\
\hline Recreational physical activity (MET-minutes/week) & $543.7(750.0)$ & $850.8(912.0)$ & .07 \\
\hline Moderate physical activity (MET-minutes/week) & $1246.0(1495.6)$ & $980.2(1430.8)$ & .10 \\
\hline Vigorous physical activity (MET-minutes/week) & $22.5(115.2)$ & $16.4(108.5)$ & $>.99$ \\
\hline Walking physical activity (MET-minutes/week) & $795.6(1073.5)$ & $944.3(1013.9)$ & .17 \\
\hline Sitting time (minutes/week) & $2250.6(1149.2)$ & $1703.6(853.3)$ & .004 \\
\hline Achieving recommendations (Yes), n (\%) & $34(69)$ & $34(77)$ & .26 \\
\hline \multicolumn{4}{|l|}{ Physical fitness, mean (SD) } \\
\hline 6-minute walking test $(6 \mathrm{MWD})(\mathrm{m})^{\mathrm{d}}$ & $451.6(99.7)$ & $482.6(106.3)$ & $<.001$ \\
\hline $\mathrm{VO}_{2 \text { peak }}(\mathrm{mL} \cdot \mathrm{min} / \mathrm{kg})^{\mathrm{e}}$ & $13.7(4.4)$ & $13.5(6.0)$ & .71 \\
\hline Heart rate $(\text { beats } / \mathrm{min})^{\mathrm{f}}$ & $119.1(18.6)$ & $103.2(19.3)$ & .11 \\
\hline Handgrip strength, left $(\mathrm{kg})^{\mathrm{g}}$ & $30.1(35.3)$ & $24.1(4.4)$ & .25 \\
\hline Handgrip strength, right $(\mathrm{kg})^{\mathrm{g}}$ & $26.2(6.1)$ & $26.2(4.3)$ & .17 \\
\hline Isometric quadriceps strength $(\mathrm{N})^{\mathrm{h}}$ & $194.2(69.1)$ & $236.4(78.6)$ & $<.001$ \\
\hline \multicolumn{4}{|l|}{ Anthropometrics } \\
\hline Weight (kg), mean (SD) & $69.1(15.7)$ & $67.4(15.4)$ & .03 \\
\hline \multicolumn{4}{|l|}{ Body mass index (BMI) $\left(\mathrm{kg} / \mathrm{m}^{2}\right)$} \\
\hline Mean (SD) & $26.1(5.8)$ & $25.4(5.8)$ & .03 \\
\hline Underweight (BMI <18.5kg/m²), n (\%) & $3(6)$ & $3(7)$ & $\mathrm{N} / \mathrm{A}^{\mathrm{i}}$ \\
\hline Normal weight $\left(\mathrm{BMI}<25 \mathrm{~kg} / \mathrm{m}^{2}\right), \mathrm{n}(\%)$ & $20(41)$ & $21(48)$ & N/A \\
\hline Overweight $\left(\mathrm{BMI}=25-30 \mathrm{~kg} / \mathrm{m}^{2}\right), \mathrm{n}(\%)$ & $16(33)$ & $12(27)$ & N/A \\
\hline Obese (BMI > $\left.30 \mathrm{~kg} / \mathrm{m}^{2}\right), \mathrm{n}(\%)$ & $10(20)$ & $8(18)$ & N/A \\
\hline Waist circumference (cm), mean (SD) & $91.4(16.6)$ & $90.4(13.5)$ & .23 \\
\hline Hip circumference $(\mathrm{cm})^{\mathrm{j}}$, mean $(\mathrm{SD})$ & $103.0(11.3)$ & $99.0(11.8)$ & $<.001$ \\
\hline Metabolic risk, n (\%) & & & .51 \\
\hline At risk of insulin resistance & $5(11)$ & $6(14)$ & N/A \\
\hline At risk of cardiovascular disease & $27(57)$ & $27(61)$ & N/A \\
\hline No risk & $15(32)$ & $11(25)$ & N/A \\
\hline
\end{tabular}




\begin{tabular}{|c|c|c|c|}
\hline Measure & $\begin{array}{l}\text { Baseline }(\mathrm{N}=49) \text {, } \\
\text { mean }(\mathrm{SD}) \text { or } \mathrm{n}(\%)\end{array}$ & $\begin{array}{l}\text { End of the study }(\mathrm{N}=44) \text {, } \\
\text { mean }(\mathrm{SD}) \text { or } \mathrm{n}(\%)\end{array}$ & $P$ value \\
\hline Global health, mean (SD) & $62.7(20.6)$ & $63.5(23.2)$ & .74 \\
\hline \multicolumn{4}{|l|}{ Function scales, mean (SD) } \\
\hline Physical & $76.3(22.4)$ & $82.0(17.1)$ & 17 \\
\hline Role & $67.4(31.9)$ & $74.0(28.0)$ & .18 \\
\hline Emotional & $67.8(25.4)$ & 70.7 (24.6) & .47 \\
\hline Cognitive & $77.8(25.1)$ & $79.6(20.9)$ & .77 \\
\hline Social & $72.7(31.6)$ & $77.3(30.1)$ & .96 \\
\hline \multicolumn{4}{|c|}{ Symptom scales, mean (SD) } \\
\hline Fatigue & $44.2(27.4)$ & $36.9(27.6)$ & .08 \\
\hline Nausea and vomiting & $10.1(17.4)$ & $6.44(18.1)$ & .27 \\
\hline Pain & $35.1(31.6)$ & $25.4(26.3)$ & .29 \\
\hline Dyspnea & $28.5(30.7)$ & $22.7(26.7)$ & .70 \\
\hline Insomnia & $40.3(35.0)$ & $28.8(29.3)$ & .37 \\
\hline Appetite loss & $20.8(27.2)$ & $9.9(21.1)$ & .02 \\
\hline Constipation & $26.4(31.5)$ & $19.4(32.7)$ & .35 \\
\hline Diarrhea & $15.6(28.5)$ & $23.5(31.8)$ & .10 \\
\hline Financial difficulties & $13.3(24.7)$ & $15.2(25.4)$ & .48 \\
\hline \multicolumn{4}{|c|}{ Fatigue (Piper Scale), n (\%) } \\
\hline Yes & $30(61)$ & $28(61)$ & $>.99$ \\
\hline No & $19(39)$ & $18(39)$ & $>.99$ \\
\hline
\end{tabular}

${ }^{a}$ ABLE: Advanced stage Breast cancer and Lifestyle Exercise.

bIPAQ: International Physical Activity Questionnaire.

${ }^{c}$ MET: metabolic equivalent of task.

${ }^{\mathrm{d}}$ There are missing data for the $6 \mathrm{MWD}$ ( $\mathrm{n}=1$ at baseline).

${ }^{\mathrm{e}}$ There are missing data for the oxygen uptake consumption $\left(\mathrm{VO}_{2 p e a k}\right)(\mathrm{n}=14$ at baseline and $\mathrm{n}=7$ at 6 months).

${ }^{\mathrm{f}}$ There are missing data for heart rate ( $\mathrm{n}=14$ at baseline and $\mathrm{n}=7$ at 6 months).

${ }^{\mathrm{g}}$ There are missing data for handgrip strength, left ( $\mathrm{n}=2$ at baseline and $\mathrm{n}=1$ at 6 months), and right ( $\mathrm{n}=1$ at 6 months).

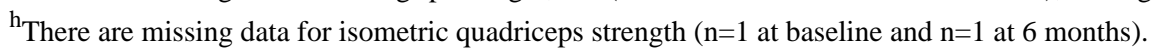

${ }^{\mathrm{i}}$ Not applicable.

${ }^{\mathrm{j}}$ There are missing data for hip circumference ( $\mathrm{n}=1$ at baseline).

${ }^{\mathrm{k}}$ There are missing data for the European Organization for Research and Treatment of Cancer 30-item Quality of Life Questionnaire (EORTC QLQ-C30) $(\mathrm{n}=1$ at baseline).

There were no statistically significant differences between participants with de novo metastatic breast cancer (14/49, 29\%) and participants with secondary metastatic breast cancer (35/49, $71 \%$ ) in terms of isometric quadriceps strength, the 6MWD, average steps per day, and total IPAQ score, neither at baseline nor at 6 months (data not shown). Participants who received hormone therapy $(27 / 49,55 \%)$ had a higher average number of daily steps compared to participants receiving chemotherapy $(22 / 49,45 \%)(P=.01)$ at baseline (data not shown). No correlations were observed between treatment variables and 6MWD, the isometric quadriceps strength, and the total physical activity score at baseline.

\section{Primary Objective of the Feasibility of the Physical Activity Intervention}

For the primary end point, among the 44 participants evaluated at 6 months, 34 (77\%, 95\% CI 62.2-88.5) participants achieved the physical activity recommendations $(\geq 630$ MET-minutes/week). Of the $31 \quad(70 \%)$ who met the recommendations at baseline, 29 met the recommendations at 6 months $(P=.27)$ (see Table 2). With respect to the use of the physical activity tracker, $96 \%$ of patients wore the physical activity tracker during the 6 months of the study without interruption for more than one consecutive week. 


\section{Secondary Objectives}

\section{Changes in Physical Activity Level, Physical Activity Fitness, and Number of Steps per Day}

At 6 months, the total physical activity level and the proportions of participants in low, moderate, and vigorous physical activity level categories remained stable ( $P=.66$ and $P=.42$, respectively) (see Table 2). A statistically significant decrease was observed for sitting time $(P<.01)$ and for the domestic physical activity score $(P=.01)$.

A $7 \%$ increase in the 6MWD $(P<.001)$ and a $22 \%$ increase in isometric quadriceps strength $(P<.001)$ were observed between baseline and the end of the intervention at 6 months. However, the estimated average rate of change from the unconditional growth model was not significantly different from $0(P=.75)$, indicating that no statistically significant change occurred in the number of daily steps per month throughout the study.

During the study, $54 \%$ of the study participants accumulated more than 5000 steps per day, which is the sedentary threshold. The $\mathrm{VO}_{2 \text { peak }}$, heart rate, and handgrip strength values did not change during the study $(P=.71, P=.11$, and $P=.25$, respectively) (see Table 2).

\section{Changes in Anthropometrics Measurements and Markers of Metabolic Risk}

A significant decrease in weight, BMI, and hip circumference was observed at 6 months $(-2.5, P=.03 ;-2.5 \%, P=.03$; and $-4.0 \%, P<.001$, respectively). No differences were observed for waist circumference, insulin-resistance risk, and cardiovascular risk (see Table 2).

\section{Changes in Participant-Reported Outcomes}

The quality-of-life scores remained stable for the total global health status and for all functional domains (see Table 2). A statistically significant decrease of $52 \%$ was observed for the appetite loss domain $(P=.02)$, which means that after the end of the 6-month intervention, the patients significantly regained their appetites. The global health score of quality of life at baseline for the study participants (62.7, 95\% CI 56.7-68.6) was not statistically significantly different from the reference score for participants with recurrent or metastatic breast cancer $(P=.41)$ (data not shown).

Fatigue evaluated by the symptom scale of the EORTC QLQ-C30 questionnaire decreased by $16 \%$, albeit in a nonstatistically significant manner $(P=.07)$, while the fatigue score on the Piper Scale did not vary significantly $(P>.99)$ between baseline and the end of the intervention (see Table2).

\section{Tumor Progression and Survival}

Among the 49 participants included in the analysis, 7 participants had metastatic progression during the study according to RECIST criteria.

A total of 4 participants died before the end of the intervention and 5 participants died during the subsequent follow-up until June 2018. The estimated median overall survival was not reached because more than half of participants were still living at the time of analysis. Overall survival rate at 12 months was $89.5 \%$ (95\% CI 76.3-95.1).

\section{Exploratory Analyses}

\section{Associations Between Physical Activity Fitness and Physical Activity Level}

The variations in 6MWD, isometric quadriceps strength, handgrip strength, and $\mathrm{VO}_{2 \text { peak }}$ were correlated neither with the variations of the IPAQ domain scores between baseline and 6 months, nor with the average number of steps per day.

\section{Associations Between Physical Activity and Quality of Life}

At baseline, the total IPAQ score was positively correlated with physical functioning (=.4, $P=.01)$ and social function (=.3, $P=.04$ ) (see Table 3 ). The variation in the $6 \mathrm{MWD}$ during the study was positively correlated with the variation in the physical functioning domain $(=.4, P=.01)$ and inversely correlated with the variation of dyspnea $(=-.3, P=.04)$ (see Table 4$)$. The variation in sitting time was inversely correlated with the variation in physical functioning (=-.6, $P<.001)$, role functioning (=-.3, $P=.03)$, and social functioning $(=-.5, P<.001)$ and was positively correlated with the variation in fatigue $(=.3, P=.05)$. 
Table 3. Spearman correlations between physical activity and quality of life at baseline.

\begin{tabular}{|c|c|c|c|c|c|}
\hline \multirow[t]{2}{*}{ Baseline (T1) } & \multicolumn{5}{|c|}{ Baseline (T1) } \\
\hline & $6 \mathrm{MWD}^{\mathrm{a}}$ & Isometric quadriceps strength & $\begin{array}{l}\text { Average steps per day during the first } \\
\text { month }\end{array}$ & $\begin{array}{l}\text { Total IPAQ } \\
\text { score }\end{array}$ & $\begin{array}{l}\text { Sitting } \\
\text { time }\end{array}$ \\
\hline Global health & .12 & -.05 & .27 & $.21^{\mathrm{c}}$ & $-.28^{\mathrm{c}}$ \\
\hline \multicolumn{6}{|l|}{ Function scales } \\
\hline Physical & .21 & .03 & $.42^{\mathrm{d}}$ & $.37^{\mathrm{d}}$ & $-.40^{\mathrm{d}}$ \\
\hline Social & .11 & .07 & .26 & $.30^{\mathrm{d}}$ & $-.33^{\mathrm{d}}$ \\
\hline \multicolumn{6}{|l|}{ Symptom scales } \\
\hline Fatigue & -.20 & -.04 & $-.49^{\mathrm{d}}$ & $-.24^{\mathrm{c}}$ & $.28^{\mathrm{c}}$ \\
\hline Pain & -.20 & .01 & -.26 & $-.28^{\mathrm{c}}$ & $.26^{\mathrm{c}}$ \\
\hline Dyspnea & -.20 & -.18 & $-.44^{\mathrm{d}}$ & -.20 & $.50^{\mathrm{e}}$ \\
\hline Insomnia & -.08 & .10 & $-.28^{\mathrm{c}}$ & -.15 & .20 \\
\hline Appetite loss & .01 & -.05 & $<.001$ & -.09 & -.07 \\
\hline
\end{tabular}

a6MWD: 6-minute walking distance.

${ }^{\mathrm{b}}$ IPAQ: International Physical Activity Questionnaire.

${ }^{\mathrm{c}} P=.10$.

${ }^{\mathrm{d}} P=.05$.

${ }^{\mathrm{e}} P<.001$.

Table 4. Spearman correlations between physical activity and quality of life and differences between $T 2^{\mathrm{a}}$ and $\mathrm{T}^{\mathrm{b}}$ in the $\mathrm{ABLE} \mathrm{Crial}^{\mathrm{c}}$.

\begin{tabular}{|c|c|c|c|c|c|}
\hline \multirow[t]{2}{*}{ Change between $\mathrm{T} 2$ and $\mathrm{T} 1$} & \multicolumn{5}{|c|}{ Variation between $\mathrm{T} 2$ and $\mathrm{T} 1$} \\
\hline & $6 \mathrm{MWD}^{\mathrm{d}}$ & $\begin{array}{l}\text { Isometric quadriceps } \\
\text { strength }\end{array}$ & $\begin{array}{l}\text { Average steps per day during the last } \\
\text { month-first month }\end{array}$ & $\begin{array}{l}\text { Total IPAQ } \\
\text { score }\end{array}$ & $\begin{array}{l}\text { Sitting } \\
\text { time }\end{array}$ \\
\hline Global health & .13 & .07 & .27 & .07 & -.25 \\
\hline \multicolumn{6}{|l|}{ Function scales } \\
\hline Physical & $.39^{\mathrm{f}}$ & .11 & .13 & .13 & $-.55^{\mathrm{g}}$ \\
\hline Social & .14 & -.12 & .09 & .21 & $-.49^{\mathrm{f}}$ \\
\hline \multicolumn{6}{|l|}{ Symptom scales } \\
\hline Fatigue & .0 & .08 & $-.41^{\mathrm{h}}$ & .08 & $.31^{\mathrm{f}}$ \\
\hline Dyspnea & $-.32^{\mathrm{f}}$ & .01 & $.54^{\mathrm{f}}$ & -.02 & .24 \\
\hline Insomnia & .01 & $.43^{\mathrm{f}}$ & .26 & -.08 & .11 \\
\hline Appetite loss & -.10 & .20 & .17 & -.19 & -.02 \\
\hline
\end{tabular}

${ }^{\mathrm{a}} \mathrm{T} 2$ : end of the intervention at 6 months.

${ }^{\mathrm{b}} \mathrm{T} 1$ : baseline.

${ }^{c}$ ABLE: Advanced stage Breast cancer and Lifestyle Exercise.

${ }_{6}$ MWD: 6-minute walking distance.

${ }^{\mathrm{e}}$ IPAQ: International Physical Activity Questionnaire.

${ }^{\mathrm{f}} P=.05$.

$\mathrm{g}_{P<.001 .}$

${ }^{\mathrm{h}} P=.10$. 


\section{Discussion}

\section{Principal Findings}

The ABLE Trial is the first European study to investigate a physical activity intervention for patients with metastatic breast cancer and to obtain preliminary data on anthropometrics, functional fitness, physical activity level, sedentary behavior, quality of life, fatigue, and tumor progression. One of the key findings is the high participation rate among women eligible for this trial (94\%), stressing the willingness of the targeted population to participate in physical activity interventions. The low attrition and high adherence clearly demonstrated the feasibility of the proposed physical activity intervention in women with metastatic breast cancer. While a deterioration of the physical activity level and quality of life would have been expected due to treatment and disease [4,31,32], women maintained their physical activity levels and number of daily steps as well as their quality of life. Women further significantly increased their physical fitness and strength.

Overall, the ABLE Trial study population was relatively physically active, since $69 \%$ of the participants met the physical activity recommendations at baseline and $47 \%$ were considered moderately active. Although the heterogeneity of the physical activity-level assessments in five physical activity intervention studies makes direct comparisons difficult, the physical activity level of women in these studies was generally lower and below physical activity recommendations [33-37]. A randomized controlled study of 101 patients with metastatic breast cancer has highlighted the moderate level of physical activity of these participants (57.5 minutes per week for the exercise group and 79.2 minutes per week for the control group) [34]. The ABLE Trial participants' ages and clinical situations were similar to those of previous study participants who mainly had secondary metastatic breast cancer and mostly bone metastases $[12,33,38,39]$. The ABLE Trial participants had a slightly lower mean BMI $\left(26.1 \mathrm{~kg} / \mathrm{m}^{2}\right)$ than women with metastatic breast cancer in four other studies that provided this information (ranging from 27.2 to $28 \mathrm{~kg} / \mathrm{m}^{2}$ ) [33,37,40,41].

\section{Recruitment, Attrition, and Adherence}

The recruitment rate in the ABLE Trial (94\%) was particularly high among eligible patients and was superior compared to the recruitment rate in 12 studies of patients with metastatic cancer ranging from $26 \%$ to $86 \%$ (average $49 \%$ ) as well as three studies of patients with metastatic breast cancer $(61 \%-65 \%)$ that provided this information $[40,42,43]$. The high recruitment rate in the ABLE Trial might be explained by the flexibility and simplicity of the intervention that was individualized to each participant as well as the regular weekly feedback provided to participants. In addition, the Centre Léon Bérard offers a physical activity program, and clinicians there are supportive of patients exercising during and after cancer treatments. The ABLE Trial also had very low attrition and excellent adherence. In contrast, Dittus et al reported a high attrition rate, ranging from $11 \%$ to $54 \%$ in 23 studies reporting this information [10]. Furthermore, three other studies of patients with metastatic breast cancer had lower adherence rates $(63 \%-75 \%)$ compared to the ABLE Trial $[34,41]$. To increase adherence in home-based physical activity interventions, weekly calls and monthly home visits were performed as recommended by Headley et al [35]. Furthermore, previous research has shown that the majority of breast cancer survivors would like to use a physical activity mobile app and $90 \%$ would find a physical activity tracker useful to monitor and increase physical activity [44].

\section{Physical Fitness}

The observed statistically significant improvement in physical fitness in the ABLE Trial was consistent with the improvement in physical function reported in most other studies, though the outcome measures varied widely [10]. The exception was the study that Ligibel and colleagues performed in a home-based intervention in which no statistically significant improvements in aerobic capacity were found [34]. While the statistically significant decreases in weight and hip circumference observed in the ABLE Trial were significantly correlated with increased 6MWD, we cannot exclude that it might also be attributable to metastatic progression rather than to the benefits of the physical activity intervention [45,46]. The statistically significant improvement observed in isometric quadriceps strength in this study is consistent with the findings of the review by Dittus et al [10], where significant improvements of strength were reported in 11 out of 12 studies; this improvement was also consistent with the results of two cross-sectional studies of patients with metastatic breast cancer that found increased strength through physical activity interventions [37,40]. While women in the ABLE Trial maintained their level of physical activity and number of daily steps, their sitting time significantly decreased. This result is an important finding since greater total sedentary time has been shown to be significantly inversely associated with physical quality of life and associated with increased mortality in women with nonmetastatic breast cancer $[47,48]$.

\section{Quality of Life}

Participants' quality of life at baseline in the ABLE Trial was similar to that of three other studies in women with metastatic breast cancer $[34,37,40]$ and similar to the reference score for patients with recurrent or metastatic breast cancer [31]. The maintenance of overall quality of life in the ABLE Trial was consistent with a systematic review conducted in metastatic cancer showing that quality of life is maintained following physical activity interventions [10], while a decline is usually observed with disease progression and treatment in patients with metastatic breast cancer [4,31]. The ABLE Trial suggests that an increase in the physical activity capacity and a decrease in the sedentary behavior in this population may counteract the detrimental effect of the disease on quality of life [11].

\section{Fatigue}

Fatigue is one of the most common symptoms described by patients with metastatic breast cancer [49]. Fatigue at baseline was less frequent in the ABLE Trial (61\%) than in other studies of metastatic cancer patients (92\%), possibly due to the study population of the ABLE Trial, which was limited to patients with de novo or secondary metastatic breast cancer diagnosed within the last 3 months [19]. But the effects of physical activity on fatigue in patients with metastatic breast cancer remains 
unclear [10]. While two studies have found a significant decrease in fatigue after a physical activity intervention [42,49], one has shown that fatigue increased over time despite a physical activity intervention-though, was less marked for the intervention group compared to the control group [35] — and a third trial was negative [34]. Maintaining the same level of fatigue, versus having it increase, through physical activity despite treatment and progression of the disease is an important clinical challenge.

\section{Strengths and Limitations}

The strengths of the ABLE Trial were the individualized intervention, the high recruitment rate, low attrition, and excellent adherence to the physical activity intervention. Activity trackers are innovative tools that can be easily used in everyday life to objectively measure patients' physical activity, such as distance travelled and number of steps.

The limitations of the ABLE Trial include the lack of a control group, which restricts assessments of the efficacy of the intervention; the small sample size, which reduces study power; the single-centered design and the select study population, which limit the study generalizability; the restriction to aerobic exercise training only; and the type of physical fitness tests used. The fitness assessments had some limitations in this study population since patients could not achieve maximal effort because of their painful bone metastases. Moreover, there is a discrepancy between the improvement in muscle function that is reflected in walking and quadriceps tests and the reported level of physical activity. Patients may also have been more confident in the postintervention tests because they knew the tests' protocol unlike at the time of inclusion. However, in any case it is still positive to have an improvement in muscle function that allows you to maintain a certain degree of autonomy. While the benefits of resistance exercise have been highlighted in various studies, the ABLE Trial did not include any resistance exercise training recommendations that could have further increased muscle mass $[10,38]$. A combined intervention with a flexible program based on steps recommendations and resistance exercises would ideally be investigated in a future randomized controlled trial. Concerning the physical activity questionnaire, it has been recognized in various scientific publications that physical activity questionnaires have several limitations and tend to under- or overestimate physical activity [50,51]. In addition, contrary to our initial hypothesis, the patients in the study already had a good level of physical activity at the time of inclusion, which did not allow us to show any improvement at the end of the study.

\section{Conclusions}

The ABLE Trial was the first study to propose a flexible, home-based, exercise intervention that used activity trackers in women with metastatic breast cancer. The improvements in physical fitness considered as clinically significant for the 6MWD and quadriceps extension strength may suggest that this 6-month physical activity intervention contributes to maintaining quality of life and physical fitness, despite the detrimental effect of treatments and disease progression. Maintaining functional capacity in these patients is all the more important to perform daily activities despite the physical deconditioning [10]. These preliminary results open new research possibilities to assess, through a randomized controlled trial, the effect of a flexible physical activity intervention based on steps recommendations, physical activity level, physical fitness, quality of life, fatigue, and tumor progression. Some cancer organizations are beginning to recognize that there is merit to encourage patients with metastatic breast cancer to be more active and to continue daily physical activity as much as possible [52]. Future research is needed to define the exact type, dose, and timing of physical activity interventions that are most beneficial to patients with metastatic disease to improve their quality and quantity of life.

\section{Acknowledgments}

The authors would like to acknowledge the contribution of Nokia for providing activity trackers, free of charge, for participants and the contribution of Florian Celli for the creation of the study logo and patient brochures. LD was supported by a research grant from the French League Against Cancer. The study was funded by the Cancéropôle Lyon Auvergne Rhône-Alpes, via the association Odyssea and Activ'Ra.

\section{Conflicts of Interest}

None declared.

\section{References}

1. O'Shaughnessy J. Extending survival with chemotherapy in metastatic breast cancer. Oncologist 2005;10 Suppl 3:20-29 [FREE Full text] [doi: 10.1634/theoncologist.10-90003-20] [Medline: 16368868]

2. Diaby V, Tawk R, Sanogo V, Xiao H, Montero AJ. A review of systematic reviews of the cost-effectiveness of hormone therapy, chemotherapy, and targeted therapy for breast cancer. Breast Cancer Res Treat 2015 May;151(1):27-40 [FREE Full text] [doi: 10.1007/s10549-015-3383-6] [Medline: 25893588]

3. Cardoso F, Costa A, Senkus E, Aapro M, André F, Barrios CH, et al. 3rd ESO-ESMO International Consensus Guidelines for Advanced Breast Cancer (ABC 3). Ann Oncol 2017 Jan 01;28(1):16-33 [FREE Full text] [doi: 10.1093/annonc/mdw544] [Medline: 28177437]

4. Cardoso F, Spence D, Mertz S, Corneliussen-James D, Sabelko K, Gralow J, et al. Global analysis of advanced/metastatic breast cancer: Decade report (2005-2015). Breast 2018 Jun;39:131-138. [doi: 10.1016/j.breast.2018.03.002] [Medline: 29679849] 
5. Rautalin M, Färkkilä N, Sintonen H, Saarto T, Taari K, Jahkola T, et al. Health-related quality of life in different states of breast cancer: Comparing different instruments. Acta Oncol 2018 May;57(5):622-628. [doi: 10.1080/0284186X.2017.1400683] [Medline: 29140139]

6. Dimeo FC. Effects of exercise on cancer-related fatigue. Cancer 2001 Sep 15;92(6 Suppl):1689-1693. [doi: 10.1002/1097-0142(20010915)92:6+<1689::aid-cncr1498>3.0.co;2-h] [Medline: 11598888]

7. Speck RM, Courneya KS, Mâsse LC, Duval S, Schmitz KH. An update of controlled physical activity trials in cancer survivors: A systematic review and meta-analysis. J Cancer Surviv 2010 Jun;4(2):87-100. [doi: 10.1007/s11764-009-0110-5] [Medline: 20052559]

8. Velthuis MJ, Agasi-Idenburg SC, Aufdemkampe G, Wittink HM. The effect of physical exercise on cancer-related fatigue during cancer treatment: A meta-analysis of randomised controlled trials. Clin Oncol (R Coll Radiol) 2010 Apr;22(3):208-221. [doi: 10.1016/j.clon.2009.12.005] [Medline: 20110159]

9. Lowe SS, Watanabe SM, Baracos VE, Courneya KS. Physical activity interests and preferences in palliative cancer patients. Support Care Cancer 2010 Nov;18(11):1469-1475. [doi: 10.1007/s00520-009-0770-8] [Medline: 19902273]

10. Dittus KL, Gramling RE, Ades PA. Exercise interventions for individuals with advanced cancer: A systematic review. Prev Med 2017 Nov;104:124-132. [doi: 10.1016/j.ypmed.2017.07.015] [Medline: 28716654]

11. Physical Activity in Patients With Metastatic Bone Disease: Guidance for Healthcare Professionals. London, UK: Macmillan Cancer Support; 2018. URL: https://www.macmillan.org.uk/ images/

physical-activity-for-people-with-metastatic-bone-disease-guidance tcm9-326004.pdf [accessed 2019-11-28]

12. Lowe SS, Watanabe SM, Courneya KS. Physical activity as a supportive care intervention in palliative cancer patients: A systematic review. J Support Oncol 2009;7(1):27-34. [Medline: 19278175]

13. Wright SP, Hall Brown TS, Collier SR, Sandberg K. How consumer physical activity monitors could transform human physiology research. Am J Physiol Regul Integr Comp Physiol 2017 Mar 01;312(3):R358-R367 [FREE Full text] [doi: 10.1152/ajpregu.00349.2016] [Medline: 28052867]

14. Kooiman TJ, Dontje ML, Sprenger SR, Krijnen WP, van der Schans CP, de Groot M. Reliability and validity of ten consumer activity trackers. BMC Sports Sci Med Rehabil 2015;7:24 [FREE Full text] [doi: 10.1186/s13102-015-0018-5] [Medline: 26464801]

15. Sullivan AN, Lachman ME. Behavior change with fitness technology in sedentary adults: A review of the evidence for increasing physical activity. Front Public Health 2016;4:289 [FREE Full text] [doi: 10.3389/fpubh.2016.00289] [Medline: 28123997]

16. Tudor-Locke C, Bassett DR. How many steps/day are enough? Preliminary pedometer indices for public health. Sports Med 2004;34(1):1-8. [doi: 10.2165/00007256-200434010-00001] [Medline: 14715035]

17. Schmid D, Leitzmann MF. Association between physical activity and mortality among breast cancer and colorectal cancer survivors: A systematic review and meta-analysis. Ann Oncol 2014 Jul;25(7):1293-1311. [doi: 10.1093/annonc/mdu012] [Medline: 24644304]

18. Tudor-Locke C, Craig CL, Aoyagi Y, Bell RC, Croteau KA, De Bourdeaudhuij I, et al. How many steps/day are enough? For older adults and special populations. Int J Behav Nutr Phys Act 2011 Jul 28;8:80 [FREE Full text] [doi: 10.1186/1479-5868-8-80] [Medline: 21798044]

19. Delrieu L, Pérol O, Fervers B, Friedenreich C, Vallance J, Febvey-Combes O, et al. A personalized physical activity program with activity trackers and a mobile phone app for patients with metastatic breast cancer: Protocol for a single-arm feasibility trial. JMIR Res Protoc 2018 Aug 30;7(8):e10487 [FREE Full text] [doi: 10.2196/10487] [Medline: 30166274]

20. The Lancet Oncology. Exercise and cancer treatment: Balancing patient needs. Lancet Oncol 2018 Jun;19(6):715. [doi: $10.1016 / \mathrm{s} 1470-2045(18) 30376-0]$

21. World Health Organization. Noncommunicable Diseases and Mental Health Cluster. Who STEPS Surveillance Manual: The WHO STEPwise Approach to Chronic Disease Risk Factor Surveillance. Geneva, Switzerland: World Health Organization; 2005. URL: https://apps.who.int/iris/bitstream/handle/10665/43376/9241593830 eng. pdf? sequence $=1 \&$ is Allowed=y [accessed 2019-11-28]

22. Crinière L, Lhommet C, Caille A, Giraudeau B, Lecomte P, Couet C, et al. Reproducibility and validity of the French version of the long international physical activity questionnaire in patients with type 2 diabetes. J Phys Act Health 2011 Aug;8(6):858-865. [doi: 10.1123/jpah.8.6.858] [Medline: 21832302]

23. Eisenhauer EA, Therasse P, Bogaerts J, Schwartz LH, Sargent D, Ford R, et al. New response evaluation criteria in solid tumours: Revised RECIST guideline (version 1.1). Eur J Cancer 2009 Jan;45(2):228-247. [doi: 10.1016/j.ejca.2008.10.026] [Medline: 19097774]

24. Savva C, Giakas G, Efstathiou M, Karagiannis C. Test-retest reliability of handgrip strength measurement using a hydraulic hand dynamometer in patients with cervical radiculopathy. J Manipulative Physiol Ther 2014;37(3):206-210. [doi: 10.1016/j.jmpt.2014.02.001] [Medline: 24630769]

25. Ashwell M, Gibson S. Waist to height ratio is a simple and effective obesity screening tool for cardiovascular risk factors: Analysis of data from the British National Diet And Nutrition Survey of adults aged 19-64 years. Obes Facts 2009;2(2):97-103 [FREE Full text] [doi: 10.1159/000203363] [Medline: 20054212] 
26. Alberti KG, Zimmet P, Shaw J. Metabolic syndrome: A new world-wide definition. A Consensus Statement from the International Diabetes Federation. Diabet Med 2006 May;23(5):469-480. [doi: 10.1111/j.1464-5491.2006.01858.x] [Medline: $\underline{16681555]}$

27. Hjermstad MJ, Fossa SD, Bjordal K, Kaasa S. Test/retest study of the European Organization for Research and Treatment of Cancer Core Quality-of-Life Questionnaire. J Clin Oncol 1995 May;13(5):1249-1254. [doi: 10.1200/JCO.1995.13.5.1249] [Medline: 7738629]

28. Piper BF, Dibble SL, Dodd MJ, Weiss MC, Slaughter RE, Paul SM. The revised Piper Fatigue Scale: Psychometric evaluation in women with breast cancer. Oncol Nurs Forum 1998 May;25(4):677-684. [Medline: 9599351]

29. Sass C, Moulin J, Guéguen R, Abric L, Dauphinot V, Dupré C, et al. Bulletin Épidémiologique Hebdomadaire. 2006 Apr 04. Le score Epices: Un score individuel de précarité. Construction du score et mesure des relations avec des données de santé, dans une population de 197389 personnes. URL: https://bdsp-ehesp.inist.fr/vibad/controllers/ getNoticePDF.php?path=Invs/BEH/2006/14/14.pdf [accessed 2019-11-28]

30. Labbe E, Blanquet M, Gerbaud L, Poirier G, Sass C, Vendittelli F, et al. A new reliable index to measure individual deprivation: The EPICES score. Eur J Public Health 2015 Aug;25(4):604-609. [doi: 10.1093/eurpub/cku231] [Medline: 25624273]

31. Scott NW, Fayers PM, Aaronson NK, Bottomley A, de Graeff A, Groenvold M, on behalf of the EORTC Quality of Life Group. EORTC QLQ-C30 Reference Values. Brussels, Belgium: European Organisation for Research and Treatment of Cancer (EORTC) Quality of Life Group; 2008 Jul. URL: https://www.eortc.org/app/uploads/sites/2/2018/02/ reference_values_manual2008.pdf [accessed 2019-11-28]

32. Foucaut A, Berthouze SE, Touillaud M, Morelle M, Bourne-Branchu V, Kempf-Lépine AS, et al. Deterioration of physical activity level and metabolic risk factors after early-stage breast cancer diagnosis. Cancer Nurs 2015;38(4):E1-E9. [doi: 10.1097/NCC.0000000000000187] [Medline: 25207592]

33. Sheean P, Kabir C, Rao R, Hoskins K, Stolley M. Exploring diet, physical activity, and quality of life in females with metastatic breast cancer: A pilot study to support future intervention. J Acad Nutr Diet 2015 Oct;115(10):1690-1698 [FREE Full text] [doi: 10.1016/j.jand.2015.03.017] [Medline: 25975457]

34. Ligibel JA, Giobbie-Hurder A, Shockro L, Campbell N, Partridge AH, Tolaney SM, et al. Randomized trial of a physical activity intervention in women with metastatic breast cancer. Cancer 2016 Apr 15;122(8):1169-1177 [FREE Full text] [doi: 10.1002/cncr.29899] [Medline: 26872302]

35. Headley JA, Ownby KK, John LD. The effect of seated exercise on fatigue and quality of life in women with advanced breast cancer. Oncol Nurs Forum 2004 Sep;31(5):977-983. [doi: 10.1188/04.ONF.977-983] [Medline: 15378098]

36. Oldervoll LM, Loge JH, Lydersen S, Paltiel H, Asp MB, Nygaard UV, et al. Physical exercise for cancer patients with advanced disease: A randomized controlled trial. Oncologist 2011;16(11):1649-1657 [FREE Full text] [doi: 10.1634/theoncologist.2011-0133] [Medline: 21948693]

37. Yee J, Davis GM, Beith JM, Wilcken N, Currow D, Emery J, et al. Physical activity and fitness in women with metastatic breast cancer. J Cancer Surviv 2014 Dec;8(4):647-656. [doi: 10.1007/s11764-014-0378-y] [Medline: 24986228]

38. Cormie P, Newton RU, Spry N, Joseph D, Taaffe DR, Galvão DA. Safety and efficacy of resistance exercise in prostate cancer patients with bone metastases. Prostate Cancer Prostatic Dis 2015 Jun;18(2):196. [doi: 10.1038/pcan.2015.6] [Medline: 25964200]

39. Cheville AL, Troxel AB, Basford JR, Kornblith AB. Prevalence and treatment patterns of physical impairments in patients with metastatic breast cancer. J Clin Oncol 2008 Jun 01;26(16):2621-2629 [FREE Full text] [doi: 10.1200/JCO.2007.12.3075] [Medline: 18509174]

40. Kokkonen K, Saarto T, Mäkinen T, Pohjola L, Kautio H, Järvenpää S, et al. The functional capacity and quality of life of women with advanced breast cancer. Breast Cancer 2017 Jan;24(1):128-136. [doi: 10.1007/s12282-016-0687-2] [Medline: 27002988]

41. Scott JM, Iyengar NM, Nilsen TS, Michalski M, Thomas SM, Herndon J, et al. Feasibility, safety, and efficacy of aerobic training in pretreated patients with metastatic breast cancer: A randomized controlled trial. Cancer 2018 Jun 15;124(12):2552-2560 [FREE Full text] [doi: 10.1002/cncr.31368] [Medline: 29624641]

42. Oldervoll LM, Loge JH, Paltiel H, Asp MB, Vidvei U, Wiken AN, et al. The effect of a physical exercise program in palliative care: A phase II study. J Pain Symptom Manage 2006 May;31(5):421-430. [doi:

10.1016/j.jpainsymman.2005.10.004] [Medline: 16716872]

43. Gulde I, Oldervoll LM, Martin C. Palliative cancer patients' experience of physical activity. J Palliat Care 2011;27(4):296-302. [Medline: 22372284]

44. Phillips SM, Conroy DE, Keadle SK, Pellegrini CA, Lloyd GR, Penedo FJ, et al. Breast cancer survivors' preferences for technology-supported exercise interventions. Support Care Cancer 2017 Oct;25(10):3243-3252. [doi: 10.1007/s00520-017-3735-3] [Medline: 28470368]

45. Prado CM, Baracos VE, McCargar LJ, Reiman T, Mourtzakis M, Tonkin K, et al. Sarcopenia as a determinant of chemotherapy toxicity and time to tumor progression in metastatic breast cancer patients receiving capecitabine treatment. Clin Cancer Res 2009 Apr 15;15(8):2920-2926 [FREE Full text] [doi: 10.1158/1078-0432.CCR-08-2242] [Medline: 19351764] 
46. Blauwhoff-Buskermolen S, Langius JAE, Becker A, Verheul HMW, de van der Schueren MAE. The influence of different muscle mass measurements on the diagnosis of cancer cachexia. J Cachexia Sarcopenia Muscle 2017 Aug;8(4):615-622 [FREE Full text] [doi: 10.1002/jcsm.12200] [Medline: 28447434]

47. Hartman SJ, Marinac CR, Bellettiere J, Godbole S, Natarajan L, Patterson RE, et al. Objectively measured sedentary behavior and quality of life among survivors of early stage breast cancer. Support Care Cancer 2017 Aug;25(8):2495-2503 [FREE Full text] [doi: 10.1007/s00520-017-3657-0] [Medline: 28326507]

48. Nelson SH, Marinac CR, Patterson RE, Nechuta SJ, Flatt SW, Caan BJ, et al. Impact of very low physical activity, BMI, and comorbidities on mortality among breast cancer survivors. Breast Cancer Res Treat 2016 Feb;155(3):551-557 [FREE Full text] [doi: 10.1007/s10549-016-3694-2] [Medline: 26861056]

49. Yennurajalingam S, Palmer JL, Zhang T, Poulter V, Bruera E. Association between fatigue and other cancer-related symptoms in patients with advanced cancer. Support Care Cancer 2008 Oct;16(10):1125-1130. [doi:

10.1007/s00520-008-0466-5] [Medline: 18504622]

50. Prince SA, Adamo KB, Hamel ME, Hardt J, Connor Gorber S, Tremblay M. A comparison of direct versus self-report measures for assessing physical activity in adults: A systematic review. Int J Behav Nutr Phys Act 2008 Nov 06;5:56 [FREE Full text] [doi: 10.1186/1479-5868-5-56] [Medline: 18990237$]$

51. Sallis JF, Saelens BE. Assessment of physical activity by self-report: Status, limitations, and future directions. Res Q Exerc Sport 2000 Jun;71(2 Suppl):S1-S14. [Medline: 10925819]

52. Cancer.Net. Alexandria, VA: American Society of Clinical Oncology (ASCO); 2019 Apr. Breast cancer-metastatic: Living with metastatic breast cancer. URL: https://www.cancer.net/cancer-types/breast-cancer-metastatic/ living-with-metastatic-breast-cancer [accessed 2019-11-28]

\author{
Abbreviations \\ 6MWD: 6-minute walking distance \\ ABLE: Advanced stage Breast cancer and Lifestyle Exercise \\ BMI: body mass index \\ CNIL: National Commission for Data Protection and Liberties \\ EORTC: European Organization for Research and Treatment of Cancer \\ EPICES: Evaluation of Precarity and Inequalities in Health Examination Centers \\ HER2: human epidermal growth factor receptor 2 \\ IPAQ: International Physical Activity Questionnaire \\ MET: metabolic equivalent of task \\ N/A: not applicable \\ QLQ-C30: 30-item Quality of Life Questionnaire \\ RECIST: Response Evaluation Criteria In Solid Tumors \\ T1: baseline \\ T2: end of the intervention at 6 months \\ VO $_{2 \text { peak }}$ : oxygen uptake consumption
}

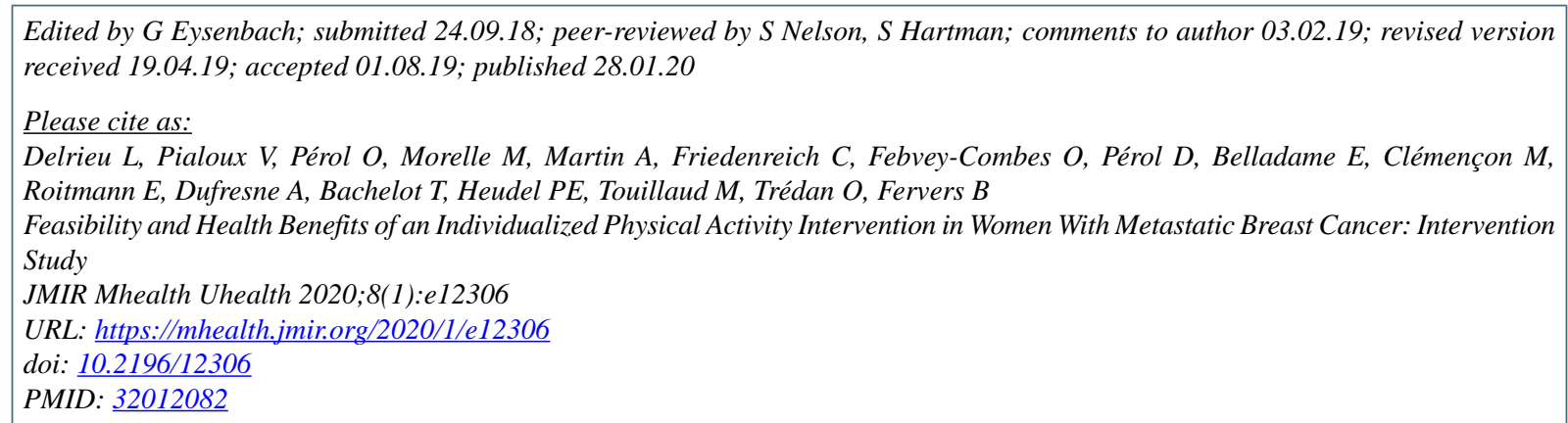

CLidia Delrieu, Vincent Pialoux, Olivia Pérol, Magali Morelle, Agnès Martin, Christine Friedenreich, Olivia Febvey-Combes, David Pérol, Elodie Belladame, Michel Clémençon, Eva Roitmann, Armelle Dufresne, Thomas Bachelot, Pierre Etienne Heudel, Marina Touillaud, Olivier Trédan, Béatrice Fervers. Originally published in JMIR mHealth and uHealth (http://mhealth.jmir.org), 28.01.2020. This is an open-access article distributed under the terms of the Creative Commons Attribution License (https://creativecommons.org/licenses/by/4.0/), which permits unrestricted use, distribution, and reproduction in any medium, 
provided the original work, first published in JMIR mHealth and uHealth, is properly cited. The complete bibliographic information, a link to the original publication on http://mhealth.jmir.org/, as well as this copyright and license information must be included. 